\title{
EXPERIMENTAL INVESTIGATION AND COMPARISION OF PLASTIC BRICKS WITH EXISTING BRICK MATERIALS
}

\author{
Dr. Suresh Kumar R, Harish Kumar M, Karthick R, Karthik B, Kermal Akash J \\ Department of Mechanical Engineering, \\ Sri Eshwar college of Engineering, Coimbatore, India
}

\begin{abstract}
Plastic waste accumulation is increasing day by day and in turn polluting the environment, particularly in high mountain villages and in places where no garbage collection system exists. Hazardous effects of plastic waste are stroked throughout the world. To address the above, an attempt is made to reduce the disposal problem of plastic waste by using plastic extruder machine. Extruder machine exploits plastic waste and changes the waste plastic into beneficial construction materials. High-density polyethylene and polyethylene bags are cleaned and added with sand. The above content is then mixed at various percentages to obtain high strength bricks retaining its thermal and sound insulation properties. This attempt is one of the best ways to avoid the accumulation of plastic waste which is anondegradable pollutant. This also saves the quantity of sand/clay consumed from the precious river beds. The plastic waste is available in surplus quantity and can be used reducing its accumulation. Also colouring agents can be added to the mixture to make desired shades. In this study, an attempt is made to evaluate the properties of the brick which is manufactured using plastic wastes and made a comparison test with the existing bricks. The results obtained also shows good sign towards replacement of bricks using the above process.
\end{abstract}

Keywords - Plastic wastes, Alternate brick, Eco bricks.

\section{INTRODUCTION}

Plastic is a non-bio-degradable substance which takes thousands of years to decompose that causes pollution to the land as well as water to the environment. The quantity of Municipal Solid Waste is expandingrapidly. It is estimated that the rate of usage of plastics is doubled for every 10 years. The usage of plastic is large in consumption and one of the major plastic wastes is polyethylene (PE). In this paper, these waste plastics are efficiently utilized in order to reduce the land space required to dump these wastes. The utilization of earth based clay material for construction is resulted in resource depletion and environmental degradation. Polyethylene bags are prepared and added with fine aggregate at various proportions to obtain high strength bricks that retain thermal and sound insulation properties. The plastic is simply compressed and shaped into durable bricks by using super-heated water. This bricks involve no glues or adhesives for use, and the non-toxic production process produces 95\% lower greenhouse gas emissions related to concrete blocks and have very high thermal and acoustic insulation. This is one of the best methods to escape from the accumulation of plastic waste. It also helps to conserve energy, decreases the overall cost of construction and the waste today can be produced wherever human's footprints be existed, and remind him that they have not chosen the suitable method for exploitation of the nature. Studies in a large stream of researches have explored impregnating waste plastics in concrete and reported positive results with multiple benefits. The present study makes a critical review of some of these findings and gathers some common useful trends in their properties.

\section{LITERATURESURVEY}

\section{A. Plastic Bricks}

Plastic wastes are becoming extremely dangerous to the environment due to their enormous production which causes harmful to the environment and its inhabitants. The most suffering due to the pollution is the marine environment. Plastic wastes generated on the land by the humans let their way to deposit on the water bodies where they cause harmful effects to the living species in the marine ecosystem and also cause detrimental effects such as flooding (Awoyera, et al., (2020) [1]). Due to the accumulation of this plastics, the species in the marine ecosystem struggles to live in it and this harmful plastic are ingested into the fishes, this causes various health issues to the human if such fishes are consumed. Cancer is the major disease caused due to this problem. In order to find an effective way to manage these plastic wastes and improve the sustainability of our environment, the limitation of the use of plastic waste for construction applications alongside the prospects is to be made. It is concluded that the use of plastic wastes for construction applications will improve the sustainability of the environment significantly and serve as a reliable source of materials for construction purposes. In addition, the use of recycled plastic wastes as a component in cementitious composites has been found to be the most beneficial as it can be used to replace all 


\section{International Journal of Engineering Applied Sciences and Technology, 2020 Vol. 4, Issue 12, ISSN No. 2455-2143, Pages 576-588 \\ Published Online April 2020 in IJEAST (http://www.ijeast.com)}

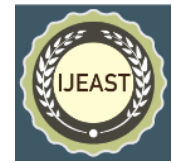

solid components of the composite. Plastics play a major role in our daily use and the wastes generated at the end of the usage of these plastics are unavoidable. Therefore, in order to properly manage these plastic wastes, there should be consider using for the various construction applications is a suitable option.

Samuel Kofi Tulashie, et al., (2020) [2] analysed the conversion of plastic wastes into pavement blocks in Ghana. The physical and chemical properties of the pit sand, sea sand, plastic wastes, and pavement block were studied. The plastic-pit sand pavement block (PPPB) had fibrous surface with smaller pore volume and grain size than the plastic-sea sand pavement block (PSPB). At $20 \%$ plastic composition, the water absorptivity of plastic-pit sand pavement block and plastic-sea sand pavement maximized at $3.98 \%$ and $4.60 \%$, respectively. The maximum compressive strengths of PPPB and PSPB were $40 \mathrm{~N} / \mathrm{mm} 2$ and 28 $\mathrm{N} / \mathrm{mm} 2$. The maximum tensile strength of PPPB (8.2 $\mathrm{N} / \mathrm{mm} 2)$ exceeded the PSPB $(6.1 \mathrm{~N} / \mathrm{mm} 2)$. Furthermore, increasing the plastic composition improved the average penetration resistance of both pavement blocks. The results showed that converting plastic wastes into pavement blocks is feasible. The amount of plastic decreased the water absorptivity of the blocks but increased the compressive strength. The maximum water absorptivity of PSPB was $15.5 \%$ higher than the PPPB. This was recorded at $20 \%$ plastic composition. From the FTIR, Quartz and Kaolin minerals were the main components of the sand samples, whereas those of the plastic wastes were polyethylene and polypropylene. The compressive and tensile strength of both blocks remained nearly constant at $80 \%$ and $90 \%$ plastic composition. The overall compressive strength, tensile strength, and penetrative resistance property of PPPB surpassed the PSPB, which make PPPB a superior constructive material to PSPB. The results suggest that it is feasible to combine pit sand with thermoplastic wastes to form pavement blocks, which could be suitable for building and construction of roads in Ghana. This would also reduce congestion of the sea and other river bodies with plastics.

Melina Gomez, et al., (2020) [3] studied the plastic fraction of waste electrical and electronic equipment (WEEEP) contains a significant amount of brominated flame retardants and heavy metals, which suppose a risk of health issues to humans and the environment. In order to transform this waste into a useful and to be non-hazardous material, they have developed a novel stabilization strategy. A core-shell recycled plastic aggregate (RPA) consisting of grinded WEEEP (core) and a mixture of cement and several additives such as a very fine aggregate, clay or activated charcoal (shell) was obtained. They proved that the coreshell strategy, in which cement-activated charcoal shell was employed, produces a stabilization of the hazardous compounds. Compression strength tests showed that recycled plastic aggregates could be used as replacement for sand in cement mortar. This effect could be solved with the use of activated charcoal as a stabilizing additive. It is important to notice that to date there is no other report about the BFRs leaching in cement matrix. Moreover, an integral applied study for the use and revalue of this type of hazardous waste for civil construction materials were presented. The results obtained with activated charcoal as a stabilizing additive opens a huge field of study for future researches on different sources and dosages of this and other additives in the manufacture of the synthetic aggregate. It is inferred that the proposed material will have good properties as thermal insulator material due to its high polymer content.

Alejandra VidalesBarriguete, et al., (2020) [4] focused on analysing the water-resistant properties of gypsum compounds with plastic cable waste added in order to determine the suitability of their use as an alternative to combat moisture problems in buildings. The test samples made were exposed to the capillary water absorption, water vapour permeability, wet chamber, water-stove cycle and total water absorption tests, and their porosimetry were also examined using the mercury porosimetry test. The results recorded that the significant decrease in water absorption and retention capacity. Thus, the material observed is a good alternative to the gypsums which is to be applied in the areas of buildings most exposed to the water and it contributes to reduce environmental impacts. With the use of plastic cable waste as aggregates in gypsum matrices, compounds with a water absorption capacity significantly lower than gypsum without plastic cable waste were achieved, while retaining, in accordance with the air permeability test, the capacity to regulate relative humidity in the indoor rooms of buildings characteristic of gypsum, as well as keeping their mechanical properties above the minimum values indicated in the regulations. Gypsum with $\mathrm{PW}$ can therefore be considered a good plaster to apply in areas of buildings with greater exposure to water, such as basement floors or ground floors on screeds, walls with recesses and even exterior walls protected by corrugated roofs, porches, etc. This would represent a decrease in the use of these natural resources by between $25 \%$ to $30 \%$, in addition to the reduction in the amount of existing plastic waste, would contribute to minimising environmental impact through building materials.

Zhiqiang Yang, et al., (2020) [5] performed industrial scale tests for the preparation of permeable bricks were carried out in a stubborn plant. The permeable bricks were firstly prepared using $82 \%$ weight ceramic waste large aggregate by experimental test. The industrial scale test was achieved based on the best conditions of the pilot test, and 100 permeable bricks having a size of $140 \mathrm{~mm}$ x $280 \mathrm{~mm}$ x $80 \mathrm{~mm}$ were successfully formed using $600 \mathrm{~kg}$ of raw materials. This formed permeable brick has a high permeability of $3.0 \mathrm{x}$ 


\section{International Journal of Engineering Applied Sciences and Technology, 2020 Vol. 4, Issue 12, ISSN No. 2455-2143, Pages 576-588 \\ Published Online April 2020 in IJEAST (http://www.ijeast.com)}

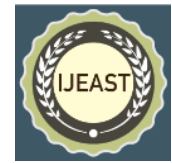

$10^{2} \mathrm{~cm} / \mathrm{s}$ and it has been found that many concluded holes are consistently dispersed within the permeable brick, which ensures the high permeability. Meanwhile, the binders make the aggregates interrelate with each other, ensuring enough mechanical strength. In this paper, the probability of using ceramic waste as aggregate and sodium silicate, cement, fly ash and clay as binder for pilot and industrial scale tests of permeable bricks producing were studied by means of bulk density, permeability, flexural strength and apparent porosity test, as well as SEM observation. The binder melts and reacts at high temperature, making a new phase plagioclase to build a good bond between the aggregates, thus improving the mechanical strength of the permeable brick.

Adeniyi Salami, et al., (2019) [6] research work was aimed at investigating the suitability of making compressed earth bricks (CEB) with a mixture of soil and striped waste plastic. Specific gravity, particle size distribution and compaction tests were carried out on the soil to determine the properties of the soil. The compressive strengths and erosion rates of the CEB made with the soil and the mixture of soil and varying proportions of striped waste plastic of two sizecategories were determined. The soil was classified as clayey sand (SC). The highest compressive strength was obtained for the CEB containing $1 \%$ waste plastic of sizes of the CEB samples stabilized with striped waste plastic, the sample containing $1 \%$ waste plastic of sizes $<6.3 \mathrm{~mm}$ also had the least erosion rate. The use of waste plastic that would have constituted an environmental nuisance has the potential to produce stronger and economical bricks for providing economical housing. The purpose of this research work was to investigate the effects of stabilizing a soil with striped waste plastic on the suitability of using the stabilized soil to produce compressed earth bricks (CEB). To improve the compressive strength and durability of CEB containing striped waste plastic, a binder such as cement, lime or another additive with adhesive properties may be mixed with the soil and striped waste plastic during the production of the CEB.

Mondal, et al., (2019) [7] exposed the performance of waste plastics impregnated bricks reported the results of experiments done on bricks made up of varying percentages of waste thermoplastics $(0-10 \%$ by weight) and sand (60 $70 \%$ by weight), holding percentages of ash and ordinary hydraulic cement constant at $15 \%$ (by weight) each. Three sortsof waste thermoplastics were used, forming three separate batches of bricks. The plastics were polycarbonates, polystyrenes, and mixed plastics. This paper also presents a regression model to predict the compressive strength of bricks at varying plastic contents. This study also introduces a new strand of research on sustainable recycling of waste thermoplastics in the context of the circular economy.
The results of the present study reveal a clear possibility of adding all kinds of waste thermoplastics in bricks with a limited compromise on mechanical properties. These bricks possess favourable properties of construction materials as they are lightweight, porous and are of high thermal resistance. Thus, while the process provides a convenient way of disposing of waste plastic, it also creates economic value in terms of energy efficiency in buildings. The process of making porous bricks as espoused in this paper is non-destructive involving no combustion or incineration. Bricks with an increasing percentage of plastics have more voids and thus are of improved thermal resistance though the compressive strength (CS) progressively reduces. Thus, bricks with waste thermoplastics are quite suitable for construction works and for energy efficient buildings for tall structures.

ManendraVaitla, et al., (2019) [8] studied the plastic wastes disposal. In India, more than 15,000 tons of plastic wastes are generated every day, of which 6,000 tons remain uncollected and scattered as per the Government statics. Reuse of bulky wastes is considered as one of the best environmental alternatives for solving the problem of disposal. One such waste is plastic, which could be used in various applications in our daily life. This paper discussed about the behaviour of concrete with partial replacement of fine aggregate with plastic wastes ranging from $15-30 \%$ with small grain size are incorporated. The blocks casted by using this concrete can be used for dividers and temporary structures. Slump test, water absorption test, water permeability test and compressive strength test were conducted on the concrete. The compressive strength of waste plastic concrete blocks has increased compared to conventional concrete blocks. The plastic wastes that can be obtained in any household, such as milk pouches, water bottles, chocolate wrappers, plastic bags etc., are collected and used as replacement for the fine aggregate in concrete. This has dual advantage which is use of waste in a nondestructive way and fulfilment of demands of concrete in large quantity without degrading natural resources like sand. Thus we conclude that this could be a substitution of the general concrete used in the above mentioned places (dividers, bedding of water bodies) and can reduce the cost of construction up to a great extinct since the amount of san used is going down. Instead of polluting the environment this takes the pollutants and helps in preserving the landfills.

Gyanendra Kumar, et al., (2019) [9] study was about the preparation of I-shape $80 \mathrm{~mm}$ recycled paver blocks (RPBs) in the factory and laboratory setup by replacing $10 \mathrm{~mm}$ natural coarse aggregates (NCA) by the coarse recycled concrete aggregates (CRCA) derived from the construction \& demolition waste. Recycled paver blocks were subjected to the visual inspection, dimension tolerance, compressive strength, water consumption and the impact test and observed that 


\section{International Journal of Engineering Applied Sciences and Technology, 2020 Vol. 4, Issue 12, ISSN No. 2455-2143, Pages 576-588 \\ Published Online April 2020 in IJEAST (http://www.ijeast.com)}

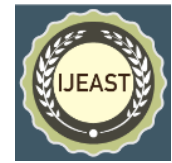

CRCA can replace up to $60 \%$ natural aggregates in Paver blocks and lab manufactured Recycled paver blocks are better than factory manufactured. This study investigated the mechanical properties of RPBs by replacing NCA with CRCA. Based on the analysis of the results, the following conclusions can be obtained: The density of the paver blocks decreased with increase in the RCA content and lab manufactured RPBs were 3 to $4 \%$ heavier or denser than factory manufactured RCBs. The compressive strength of the RPBs also decreased with increase in RCA content. Lab manufactured RCBs has $9 \%$ more compressive strength than factory manufactured. CRCA can replace up to $60 \%$ of the NCA without showing significant change in the mechanical properties. Water absorption increased with increase in the CRCA content. Lab manufactured RPBs absorb less water than factory manufactured because of better compaction and quality control measures. The impact energy decreases with increase in RCA content. Then impact energy remains same at $45 \%$ and $60 \%$ but decreased $50 \%$ again. At $75 \%$ replacement, RPBs fail without showing the sign of crack. According to this study, it is feasible to manufacture M40 paver blocks by replacing up to $60 \%$ NCA with CRCA.

JeevanGhuge,etal., (2019) [10] investigated about the use of waste plastic as construction material. Whereas concrete is the most widely used construction material all over the world. By using waste and recycled materials in concrete mixes for paver blocks becoming important to manage and treat both the solid waste generated by the industries and municipal waste. These blocks were rectangular in shape and had more or less the same size as the normal bricks. During the past five decades, the block shape has insistently developed from non-interlocking to slightly interlocking to completely interlocking to multiple interlocking shapes. Use of plastic waste which is non-biodegradable and it is rapidly growing in the surroundings and becoming threat to environment in many aspects. From this study, it is clear that plastic paver block has almost equal strength as that of ordinary one. From the obtained results it can be concluded that plastic paver block can be used in the park, footpath and yards of the residential as well as commercial building because the compressive strength is sufficient for the smooth utility of user. It reduces the plastic wastes in municipal solid waste and significant reduction of land filling, and it is possible if it takes place on a large scale.

LalzarlianaPaihte, et al., (2019) [11] reviewed the use of plastic bottles are also a significant waste management concern of the rapidly urbanizing society. Concrete and building material mostly used infrastructure for last few decades. This work is aimed at uniting these two waste products and producing an alternate for conventional bricks, thus yielding a sustainable and environment-friendly building material. Used plastic bottles were occupied with crushed recycled aggregate and anticipated water content and were wrapped. Bottles containing crushed RA with a size between $425 \mu \mathrm{m} \& 4.75 \mathrm{~mm}$. The $3.5 \%$ saline solution for 28 days did not affect the compressive strength of such bottles. Such waste material filled plastic bottles are not only cheap, zero-energy, and emission-less but also prevent the necessity of disposal of the bottles and the waste materials. Such environment-friendly and low-cost building materials are expected to pave way for low-cost housing in poor sections of the world. The crushed and recycled aggregate filled plastic bottles comparable with compressive strength to a conventional red clay brick. Bottles prepared with fine aggregates have better compressive strength as compared with larger size of aggregates. 5\% water content is the most optimal, in terms of compressive strength.

Moyo, et al., (2019) [12] performed experiment on waste of coal fly ash in the manufacture of an ammonium nitrate corrosion resistant brick. Ammonium nitrate (AN) fertilizer spillages and vapour continuously corrode the civil structures in a fertilizer. Our test results show that addition of sodium silicate to improve the brick characteristics. Generally, increase in the amount of sodium silicate added Water absorption of brick to be reduced and the compressive strength generally increased with increase in amount of sodium silicate added. Sodium silicate had the desired effect of agglomerating the particles, with the enhanced help of cement resulting in higher bonding strength with increased volume of the silicate. To increase the sand ratio in the solid aggregates enhances better packing of the solids within the structure hence increased strength. The fine coal ash particles fill into the small spaces between the sand resulting to make a compact structure which increase strength. The results further exhibited that corrosion resistance increases with the amount of sodium silicate added to the coal ash bricks. The soluble sodium silicate reacts with other metal ions present in coal ash to form the insoluble metal silicates.

Kognole, et al., (2019) [13] studied the ill effects of plastic waste. The most dangerous type of wastes is HDPE and PTE and the plastic below 50 microns is also causing a grave problem. These plastic wastes mixed in the soil and it directly affects the fertility of the soil. Currently, the large amount of plastic is dumped into sea. This plastic wastes gives risky effect on the marine life and quality of seawater also polluted by this plastic. Converting this plastic waste into construction products is the most economical solution in the present construction industry, and it is also economical and environment friendly solution which drive out the plastic wastes. Water absorption of plastic sand brick is $0 \%$. This plastic sand bricks are useful for the construction industry when compare to the Fly Ash bricks and 3rd class clay bricks. 


\section{International Journal of Engineering Applied Sciences and Technology, 2020 Vol. 4, Issue 12, ISSN No. 2455-2143, Pages 576-588 \\ Published Online April 2020 in IJEAST (http://www.ijeast.com)}

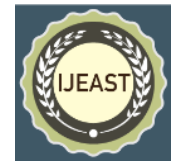

Ngoc Kien Bui, et al., (2018) [14] studied about the potential engineering of Recycled PET Bottles Waste and Recycled Woven Plastic Sack Waste fibre reinforced Recycled Aggregate Concrete (RAC). At present, the amount of Construction and Demolition Waste and plastic wastes are rapidly increasing and becoming a burden for many nations around the world. This research is an effort to reduce the amount of solid waste as a good solution for waste management and to preserve the environment. The experimental results shown that the RPET and RWS fibres have high alkali resistance in alkaline environments. The combination of Silica Fume (SF) and RPET fibre increased 3.6-9\% compressive strength, 16.9-21.5\% elastic modulus, 11.8-20.3\% splitting tensile strength, 7-15\% shear strength of RAC in comparison with RAC samples without fibre, while these values in RWS fibre reinforced RAC were lower. $\mathrm{SF}$ and the proposed mixing technique played an important role in improving properties of RAC containing $100 \%$ coarse RCA and compensated the loss of compressive strength due to recycle plastic fibre whereas RPET and RWS fibre enhanced the postcracking properties, shear strength, splitting tensile strength of RAC. The potential engineering of RPET and RWS fibre reinforced RAC can solve present environmental problems.

Zipeng Zhang, et al., (2018) [15] studied about the various parameters of the bricks and its production. This brick has been playing a significant role in the construction of various buildings for thousands of years. Even though the reliable workability and accessibility, it is widely known that the production of fired clay brick has always been a kind of energy- and resource-intensive process. This review found that firing is still the most common method to manufacture bricks, while this process involves enormous energy consumption and carbon footprint. Considering that cement and limebased calcium-silicate-hydrate bricks are also not sustainable, Geo-polymerisation is a preferable way to produce bricks, but corresponding cost and benefit analyses need to be conducted for relevant research. This paper also suggests that clay-based geo-polymer bricks could be one of the focuses of future brick-related research, and the key challenges to improve the reactivity of clay at a low cost. There are two types of innovative bricks, namely material oriented and process-oriented bricks. Clay-based geo-polymer bricks could be one of the focuses of future brick-related research, and the key challenge is to produce the clay-based geo-polymer in a less energy-intensive way.

YaziMeng, et al., (2018) [16] reviewed about the environmental concerns related to the disposal of various waste materials have escalated to a worrying level. Depending on the local industries, various types of waste are generated in huge quantities every year. The demands for more sustainable development have moreover increased the importance of green construction. In the past years, extensive study efforts have been made to recycle the wastes for possible use in the production of concrete products. This paper reviews the published research works on the use of various kinds of wastes such as recycled concrete, crushed brick, soda lime glass, cathode ray tube glass, crumb rubber, ceramic and tile waste in the production of concrete blocks. Several unique characteristics of recycled crumb rubber, plastic waste and crushed brick enhance the fire resistance, toughness, functional and insulation properties of concrete blocks. The consent of concrete blocks with standard requirements and the value-added properties have demonstrated good potential for incorporating wastes as aggregate in concrete blocks. The utilization of waste materials as a combined replacement in concrete blocks have the beneficial environmental effects of reducing the existing solid waste and lowering the consumption of natural resources commonly used as aggregates. For pavement application, wastes such as crumb rubber, plastic and GBFS can be used to enhance the abrasion, skid and freeze-thaw resistance of concrete paving blocks. The use of marine sediment waste can also promote better weathering resistance of the blocks.

Rubio de Hita, et al., (2018) [17] described the procedure for manufacturing a beam-filling piece for the construction and rehabilitation of traditional timber-beam floor structures using pieces made of cement mortars with aggregates consisting of mixed polypropylene plastic waste from urban waste collection plants. Previously the piece was manufactured, a series of mortars was produced with aggregates of recycled plastic as partial substitute for natural aggregates. These sealants were categorized in both fresh and hardened state by analysing their physical and mechanical properties. The outcomes helped to determine the best dosage for achieving the levels of resistance required by law for infill bits. The infill piece proposed in this paper can be adapted to any dimension of wood beam infill space, which enables the original construction layout of the beams to be preserved. This means that the piece can be used in floor structure improvement works that require the original floor structure geometry to be preserved by law. The application of this piece means that the existing wooden beams can be used to good effect by creating a mixed wood concrete floor structure with increased structural strength. The piece proposed is a highly ecoefficient construction solution, both enabling the use of the existing wooden beams and plastic from urban waste recycling plants.

ArvindSinghal, et al.,(2018) [18] estimated that the plastic waste will double after a decade as we use hundreds of grades of plastic in our daily life. Owed to extreme use of the clay, it shows the result of resources depletion and environmental degradation. So that we get to crush the plastic waste into fine particles and heated on a furnace. We use nugget dust as fine aggregates (size 


\section{International Journal of Engineering Applied Sciences and Technology, 2020 Vol. 4, Issue 12, ISSN No. 2455-2143, Pages 576-588 \\ Published Online April 2020 in IJEAST (http://www.ijeast.com)}

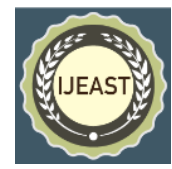

below than $4.75 \mathrm{~mm}$ ), heated on a furnace. Instantly, we mix heated plastic waste and heated stone dust and pour into mound and form bricks and tiles. Observed that the characteristics of bricks and tiles is far considerably better than normal bricks and tiles as minimum water absorption, highly compressive strength, smooth surface, unbreakable, less weight. The compressive strength of plastic sand brick is $5.6 \mathrm{~N} / \mathrm{mm} 2$ at the compressive load of $96 \mathrm{KN}$.

Arul Arulrajah, et al., (2017) [19] investigated about the vast quantities of plastic and demolition wastes generated annually by municipal and commercial industries in all developed and developing countries. The sustainable usage of recycled plastic and demolition wastes as alternative construction materials has abundant environmental and economic advantages. New prospects to the recycle plastic and demolition wastes into alternative source materials for construction industries would moderate landfill issues and significantly reduce global carbon emissions. In this study, recycled plastic waste granules were classified into three types such that Linear Low-Density Polyethylene filled with Calcium Carbonate, High Density Polyethylene and Low-Density Polyethylene were projected in blends with Crushed Brick and Reclaimed Asphalt Pavement. The blends prepared were considered in terms of strength, stiffness and resilient moduli. The plastic granules with up to 5\% were found to be suitable to use as a road construction material, when mixed in an additional amount with demolition wastes. This research reviewed that the convention of plastics as a construction material, in combination with demolition wastes will accelerate the implementation of recycled by-products by construction industries. Besides, the plastic blends were prepared without the requirement for any additional operations, such as restructuring plastic granules into fibres, hence leading to significant energy and costs savings.

Gaurav Goel, et al., (2017) [20] demonstrated the probability of incorporating degraded municipal solid waste as one of the constituents for production of fired bricks. The raw materials used certainly degraded municipal solid waste and two different soils such that laterite soil and alluvial soil were mixed together in different proportions. Specimens of these mixtures were then fired at $850^{\circ} \mathrm{C}$ and $900^{\circ} \mathrm{C}$ respectively. The various properties such as bulk density, linear reduction, loss on eruption, water absorption, compressive strength, and modulus of elasticity with respect to Indian and ASTM standard codes were studied and compared. An optimum integral mix of $20 \%$ degraded municipal solid waste with laterite or alluvial soil fired at temperature of $900^{\circ} \mathrm{C}$ was found to be most appropriate for brick production. The ultimate uptake of this study is $8 \%$ net saving in the energy consumption of external fuel by mixing $20 \%$ degraded MSW. The limits of adding degraded MSW to the soil were found to be $20 \%$ weight and a firing temperature of $900^{\circ} \mathrm{C}$ helps in achieving maximum durability of hybrid bricks. Water absorption in brick increases by $8 \%$ in laterite soil and $10 \%$ in alluvial soil for $20 \%$ integration of degraded municipal solid waste while firing at the temperature of $900^{\circ} \mathrm{C}$. Compressive strengths is noticed to decrease by $70 \%$ in laterite soil and $77 \%$ in sedimentary soil bricks for addition of $20 \%$ degraded MSW with respect to control bricks at firing temperature of $900^{\circ} \mathrm{C}$ maintaining the acceptable values. TCLP test results confirmed that fired bricks incorporated with $20 \%$ weight of degraded MSW are safe to use and can be recycled after service life.

Valeria Gregorova, et al., (2017) [21] investigated on the manufacture of lightweight concrete from cable, polystyrene and ethylene vinyl acetate waste. Ethylene Vinyl Acetate waste collected from the footwear industry, waste from electrical cable and waste polystyrene were used as an aggregate in the lightweight Concrete production. The plastic waste used was the only aggregate as well as in the combination of EVA-cable and EVA-polystyrene. The water-cement ratio of 0.50 and the cement dose of $175 \mathrm{~kg} / \mathrm{m} 3$ were used for all mixtures. The lightweight concrete was verified particularly with their density, strength and heattechnical characteristics. Increasing the content of EVA waste led to an increase in strength characteristics as well as thermal conductivity values. LWC samples containing PVC cable waste achieved the highest bulk density and therefore the lowest thermal conductivity. Though, LWCs with $100 \%$ dosage of cable did not reach the predictable strength properties. The LWCs using collective in the ratio 1:1 and the polystyrene and EVA and EVA and PVC cables reached the highest values of stress. Based on results can be concluded, that LWCs based on the recycled waste have the future in the use of combination of more wastes. Their suitable combination can lead to achieve the good thermal and mechanical properties.

Thirugnanasambantham, et al., (2017) [22] studied about the comparison and testing of plastic made bricks. Plastic is a non-bio-degradable substance which takes thousands of years to decompose and it stagnant in the land as well as water causes pollution to the environment. The amount of plastic waste in Municipal Solid Waste is increasing rapidly. It is projected that the rate of usage is double for every 10 years. The Plastic usage is large in consumption and one of this largest plastic wastes is polyethylene. The utilization of earthbased clay material occasioned in resource exhaustion and environmental degradation. Polyethylene bags are cleaned and combined with fine aggregate at various ratios to obtain high strength blocks that possess thermal and sound insulation properties. This is one of the best ways to avoid the accumulation of plastic waste. It also helps to conserve energy, diminish the global cost of construction and hence in this project, an effort is made to manufacture the plastic sand bricks by utilizing the waste plastics. Plastic sand brick holds more 


\section{International Journal of Engineering Applied Sciences and Technology, 2020 Vol. 4, Issue 12, ISSN No. 2455-2143, Pages 576-588 \\ Published Online April 2020 in IJEAST (http://www.ijeast.com)}

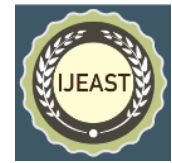

compensations which includes cost efficiency, reduction in emission of greenhouse gases, resource efficiency and so on. Plastic sand brick is also known as "Eco-Bricks" made of plastic waste which can be used for construction purposes. It rises the compressive strength when compared to fly ash bricks. By use of plastic sand bricks, the water absorption and the occurrence of alkalis was highly reduced. Due to numerous advantages further research would improve quality and durability of plastic sand bricks.

Henri Achten, et al., (2017) [23] investigated on a special polyethylene terephthalate bottle that fulfils the various conditions. The consumer goods such as bottles made of polyethylene terephthalate are usually thrown away after consumption. A huge number of this wastes usually ends up somewhere in the environment. In many developing countries this polyethylene terephthalate bottles are used in the construction purposes, mainly as fill-in material in concrete or adobe walls. In this research founded that they have produced a special PET bottle with blow-moulding technology having the good stacking features to eliminate or minimize binding medium between PET bottles and produced out of recycled PET. This special PET bottle resulted in a series produced and patented brick called PET brick. PET bricks do not seem suitable as a self-standing wall but can function as easily stackable fill-in material within a load-bearing structure. Application of PET bottles in the shape of PET bricks as building units is possible only under defined conditions. This result speaks for the possible use within catastrophic scenarios, where a water container can secondly serve as building material container. It can also bear the temperature of $70^{\circ} \mathrm{C}$ to $80^{\circ} \mathrm{C}$. These temperatures show big changes in the shape of the PET bricks and it is irreversible. While the PET bricks can withstand big forces, the change of its shape is immediate starting with relatively small loads. Consequently, the structure is not recommended for incorporation into other precise constructions, only as a filling with no load.

SankuruNareshIn, et al., (2017) [24] made an extensive study of plastic hazards in India. According to the survey made by them, sixty-seven million tons of plastic waste were generated per day, greater city like Hyderabad generated three thousand five hundred to four thousand tons per day and as per survey directed by the municipal waste management India, average of 0.5 grams' plastic waste caused by single person per day. Out of this only $25 \%$ to $30 \%$ of plastic wastes recycle efficiently, remaining seventy-five percentage of plastic waste leads to create land pollution because whatever the plastic waste generated it takes three fifty to four hundred years to decompose in the soil. Decisively, it leads to produce the environmental pollution and in the case of $25 \%$ to $30 \%$ effective recycle materials also expose some toxic element into the atmosphere so this kind of problems may be resolve by design and valuation of eco-friendly rigid pavement with plastic Bricks. This geo plastic bricks are arranged in first half of the surface path from bottom with help of brick paver. Plastic role is placed at the center of the clay brick which form as a small void andresults to a loss of strength. From getting this kind of results it can be suggested for the construction material, particularlythese can be used in rigid pavement construction.

Prem Kumar, et al., (2017) [25] addressed the significant problem in disposal of plastics and the lack towards providing absolute solutions. For solving this issue plastic were replaced in a brick to achieve the minimal strength. High-density polyethylene and polyethylene plastic bottles and bags were collected and cleaned then mixed with sand with various extents to achieve the strength of the minimal bricks and also to possess thermal and sound insulation. To forecast the strongest specimen, $0 \%$ to $20 \%$ of replacement quantity was done by crushed plastics. This results in increased the strength of structure and weight reduction of bricks was tested for compressive strength and water absorption test. Based on the comparison of conventional and fly ash plastic brick, optimal strength was investigated. This paper reviews the reduction of plastic disposal and the results are clearly shows that some part of plastics can be used in the production of bricks. The test outcomes show that the partial replacement of natural sand by crushed waste plastics at the levels of 5 to 10 percentages has good effects on compressive strength of the bricks. However, 20 percentage of replacement of waste plastics reduces the compressive strength when compared with that of the control sample. Overall, this plastic waste which makes environmental issues should be used in brick mixtures as a good substitute for natural sand.

Jahidul Islam, et al., (2016) [26] inspected the effect of plastic as an alternative coarse aggregate on various fresh and harden properties of concrete. Polyethylene terephthalate, is a thermoplastic polymer, considered as an alternative and replaced to brick chips. The PET aggregate is obtained by grinding, melting and crushing the collected waste PET bottles. The compressive strength of PAC at $0.42 \mathrm{w} / \mathrm{c}$ was replaced by $20 \%$ PET in the ratio $30.3 \mathrm{MPa}$ which is only $9 \%$ less than the NAC. Therefore, PET replaced for structural concrete member. PET aggregate concrete offered much better workability than the regular concrete, so it provides the opportunity to work with low w/c ratio and get the desired concrete strength. Though it could not be classified as a lightweight concrete still it provides a substantial advantage over the NAC by reducing the selfweight of the structure. High strength concrete is achieved by $20 \%$ PCA replaced concrete at w/c ratio of $0.42,30.3 \mathrm{MPa}$ compressive strength was achieved.

Ayse Kaya, et al., (2016) [27] investigated the Polystyrene used in a mixture of cement and tragacanth resin in order to produce a new concrete material. The 


\section{International Journal of Engineering Applied Sciences and Technology, 2020 Vol. 4, Issue 12, ISSN No. 2455-2143, Pages 576-588 \\ Published Online April 2020 in IJEAST (http://www.ijeast.com)}

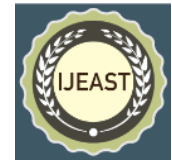

amount of the resin in the mixture was $0.5 \%$ to $1.5 \%$ of the total cement and EPS. The new samples were find the thermal and mechanical properties. It was determined that, when EPS and resin ratios of the samples increased, the density, thermal conductivity, compressive strength and tensile strength decreased, and the porosity increased. The waste EPS contained to prevent the environmental pollution and the new produced samples can be used as partition walls and floorings. The samples of artificial micro pores caused by resin, the density decreases, and total porosity increases. The lowest thermal conductivity coefficient of the samples with 20 $80 \%$ EPS and $1.5 \%$ resin samples was measured as $0.048-0.284 \mathrm{~W} / \mathrm{m} \mathrm{K}$ in samples and $0.061-0.390 \mathrm{~W} / \mathrm{m} \mathrm{K}$ in samples without resin. Using lightweight concrete and plaster mixed with EPS and resin will be lighter an earthquake damages will be allayed in addition insulation characteristic of the material will be reinforced which will ensure energy efficiency. Water absorption rates appeared below $30 \%$ so these types of materials can be cut with saw, drilled with screw and painted. The EPS aggregate cement with tragacanth resin to solve the environmental problem by recycling solid waste.

AshwiniManjunath, et al., (2016) [28] investigated recycling of $\mathrm{E}$ plastic waste as it is a valuable resource of IT industries and very hazardous wastes. To Utilization of e-plastic waste material is a partial solution to environmental and ecological problems. Use of e-plastic waste to reduces the aggregate cost, provides a good strength and reduces the landfill cost and it is energy saving techniques. The study of eplastic particles as fine and coarse aggregates in concrete with a percentage replacement ranging from $0 \%$ to $30 \%$ on the strength of concrete. Compressive, Tensile and Flexural strength of Concrete with and without E- waste plastic which exhibits a strength. The compressive strength study for Optimum Cement Content and 10\% of e-plastic content in mix yielded stability and very good in compressive strength. Plastics can be used to replace a concrete mixture and contributes to reducing the unit weight of the concrete. For a given w/c, the use of plastics has lowers the density, compressive strength and tensile strength of concrete. The effect w/c ratio of strength development is not prominent in the case of plastic concrete. The fact that the plastic to reduce the bond strength of concrete. Thus, the failure of concrete occurs due to failure of bond between the cement paste and plastic.

SinaSafinia, et al., (2016) [29] studied to observe the possibility of using plastic bottles in concrete block. The plastic bottles were to make cavities at equal distance between them in the masonry units. The 500-ml of plastic bottles are placed inside the concrete masonry units. The ASTM C140 standard for testing compressive strength of brick. This experiment shows $57 \%$ difference in the strength by using plastic bottles instead of concrete blocks. It proves the requirement for research of concrete mix design, amount of cement and properties of concrete blocks as well as other technical and non-technical features to determine the proper mix design and possibility in the production of bricks. The required amount of compressive strength and density between cylinder, bottled concrete blocks and hollow concrete blocks are acceptable. Also, the comparison to Omani hollow concrete blocks the concrete blocks with plastic bottles shown $57 \%$ higher compressive strength.

Muyen, et al., (2016) [30] proposed a reduction approache, by gaining momentum towards development of construction materials from the recycle of solid wastes. The 'bottle brick' is one such Waste PolyethyleneTerephthalate (PET) bottles packed with other dehydrated solid wastes or sand and earth has used in several countries around the world. This study investigated the properties of waste polyethylene terephthalate bottles packed with fine sand and five different sizes of waste PET bottle bricks were tested for compressive strength and largest brick have a compressive strength of $17.44 \mathrm{MPa}$. The $1000 \mathrm{ml}$ bottle brick filled cubes with 9 and 12 bottles were prepared and tested for the application purposes. These bottle brick filled in cylinders displayed double the compressive strength of conservative concrete cylinders. This technique of expending waste PET bottles as bricks has become prevalent in low income communities around the world and the present study the bottle bricks were initiate to be stronger than the conventional bricks and concrete cylinders. Considering the strength and the fairly low cost of construction they can be very effectively become the next construction material of choice too.

Rohan Muni Bajracharya, et al., (2015) [31] emphasised on exploring the mechanical behaviour of recycled mixed PSW containing HDPE, LDPE and PP using full-scale specimens. The plastic solid waste contains $16 \%$ weight of municipal solid waste, but onefourth of this wastes are recycled. One of the best ways to recycle this mixed PSW is to convert this waste into products for construction. The understanding of the mechanical behaviour of this mixed PSW under different loading conditions is important for construction material. From this test, the strength values were found to be 14.8 , $19.8,20,5.6 \mathrm{MPa}$ in tension, compression, flexure and shear respectively. The coefficient of variance was less than $10 \%$ indicating that consistent material properties can be obtained for mixed PSW. The reversal behaviour of the full-scale specimens was also forecasted using fibre model analysis and finite element modelling. Recycled mixed PSW has strength and stiffness acceptable for light load bearing construction applications and plastic deformation before failure dependent on the loading condition. Under axial tension condition the specimen yielding, followed by cracking and finally cup and cone shape to be formed. The compression specimen showed buckling and some minor 


\section{International Journal of Engineering Applied Sciences and Technology, 2020 Vol. 4, Issue 12, ISSN No. 2455-2143, Pages 576-588 \\ Published Online April 2020 in IJEAST (http://www.ijeast.com)}

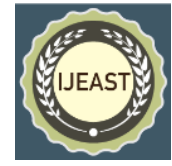

tearing. The flexural behaviour of tensile and compressive failure while a nearly vertical failure was observed under direct shear. This indicates that consistent material properties can be obtained for mixed PSW with similar composition and produced using the same method. The flexural behaviour including the nonlinear load-deflection behaviour of a full-scale beam from PSW can be reliably predicted using the constitutive material properties determined from the coupon tests.

José Nilson, et al., (2015) [32] proposed the possibility of water treatment plant waste into soilcement bricks for construction. The water treatment plants generate large amounts of municipal waste sludge's that must be discarded. The waste material sample was analysed for chemical composition, X-ray diffraction, particle size, plasticity, and organic matter. The result of the water treatment plant waste was determined by estimating different physical properties such as compressive strength, density, and water absorption. The kaolinite particles to treat water plant waste could be used for production of soil-cement bricks and to reduce the environmental impacts. The water treatment plant waste is a plastic material rich in $\mathrm{Al} 2 \mathrm{O} 3$, $\mathrm{SiO} 2, \mathrm{Fe} 2 \mathrm{O} 3$, and organic matter. This result of X-ray diffraction that waste sample is composed predominantly of kaolinite. In this work, it was demonstrated that the soil can be replaced with up to $1.25 \%$ water treatment plant waste in the plant waste in soil cement brick is associated with the increase of water absorption. The incorporation of water treatment plant waste in the production of soil-cement bricks is an excellent alternative for the reuse of materials and recycling.

Noel Deepak Shiri, et al., (2015) [33] study was about to reduce the plastic waste that is rising in the present world and design to incorporating a plastic extruder which plays a prominent part in recycling waste plastic into useful products. This work uses waste plastics and converts them into building materials with the help of an extruder, in that way reducing the plastic waste which is a key factor for environmental pollution. Presently waste plastics are efficiently converted into useful building materials like bricks, interlocks, roof tiles, railway sleepers, paving slabs, retaining blocks etc., using either single origin plastic waste material or a combination of different plastic wastes along with waste rubber powder as plaster. This work efficiently adapts waste plastic to useful building materials like building bricks and floor interlocks which can effectively reduce the environmental pollution and additional reduce the problem of waste plastics accumulated in the society. Vaguely than the waste plastics going into the landfill or incinerators it can be used as construction materials at a much lower cost after undergoing certain specific processing. It also reduces the construction cost by abolishing the use of mortar during construction by using recyclable plastic/composite bricks and floor interlocks.
The compression testing results we shows that the waste plastics material when effectively mixed with Rubber powder and Calcium Carbonate gives the highest compressive strength and sustains high compressive load.

Hui Wang, et al., (2014) [34] proposed recycling of plastic wastes is an effective way to manage and handle the plastics. Parting of polyethylene terephthalate from municipal waste plastics by head flotation combined with alkaline pretreatment was examined for recycling industry. The ideal conditions of alkaline to be pretreatment with sodium hydroxide and initiation separation of PET from acrylonitrile, polystyrene and polycarbonate efficiency to be achieved. The separation of PET from MWP by a combination of froth flotation and sink float separation. This study simplifies industrial application of plastics flotation and offers technical insights into recycling of waste plastics. Separation of PET from municipal waste plastics and orthogonal array of experiments demonstrate that the alkaline pretreatment is temperature followed by treatment of $\mathrm{NaOH}$. After alkaline pretreatment under ideal condition, flotation separation PET from ABS, PS, PVC or PC was attained with high pureness and efficiency.

Rigamonti, et al., (2014) [35] proposed a system to manage the plastic fraction, which is one of the most argued issues in the discussion on integrated municipal solid wastes. Both material and energy recovery can be achieved on such a waste stream and different separate collection schemes can be instigated. The aim is to contribute to the argument based on the analysis of different plastic recovery routes. Five circumstances were defined and modelled with a life cycle valuation approach using the EASEWASTE model. In the baseline scenario the plastic is treated as residual waste and routed partly to burning with energy recovery and partly to mechanical biological treatment. A sensitivity analysis on carried out was modelled as a first step assuming that marginal electricity and heat were based on coal and mix of fuels based on natural gas. Recycle of the plastic waste fraction contained in municipal solid waste was measured with the definition of a number of address the challenges in a critical material. In the baseline scenario plastic is treated together with the residual waste and routed to WTE and MBT.

Jonathan Taaffe, et al., (2014) [36] discussed about the issue of recycling waste plastic into use of Ecobricks for constructional purposes. The Eco-bricks are designed by packing plastic within Polyethylene Terephthalate (PET) bottles were provided for the construction. Experiments were carried out to describe the properties of these bricks. Compression test, soundness test and light transmission were considered traditional construction materials and conditions. The paper presents the first attempt to describe these bricks 


\section{International Journal of Engineering Applied Sciences and Technology, 2020 Vol. 4, Issue 12, ISSN No. 2455-2143, Pages 576-588 \\ Published Online April 2020 in IJEAST (http://www.ijeast.com)}

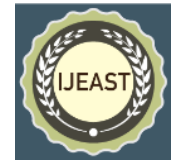

and the results encourage future use of wider extent and for various uses. It results that Eco-brick is a viable resource for construction purposes and bricks are easily manufactured. Eco-bricks have comparatively good compressive strength and weight of Eco-brick was observed to hold a relationship with load failure and specific strength. The lightweight properties of the brick to reduce the cost of transportation. The calculated Poisson's ratio was experimental to be within the range of 0.27 to 0.35 . Eco-bricks have a relatively high sound reduction index, even when compared to normal concrete block, which is a far denser material. Lightweight Ecobricks also to reduce the chances of injury during lifting of heavy materials. The bricks are non-brittle and simple recycling advancement in nature.

Wen Ten Kuo, et al., ., (2013) [37] study concentrated towards the washed municipal solid waste incinerator bottom ash for natural aggregate in concrete. The mix proportions of the concrete were first testing vertical flow test following compressive strength, bending and split tensile strength tests to be performed. The test results show the unit weight of fresh concrete made with MSWIBA was 1653 to $2080 \mathrm{~kg} / \mathrm{m} 3$. In this specimen same $w / c$ ratio with the compressive, bending and split tensile strengths all increased with the ratio of filling paste. The porosity and permeability coefficients are linearly correlated to both decrease as the filling ratio is increased. The unit weight of freshly mixed pervious concrete made using 12.5-mm washed MSWIBA was approximately 1653 to $2080 \mathrm{~kg} / \mathrm{m} 3$ and increased with increasing filling paste ratio. For pervious concrete mixes with the same $\mathrm{w} / \mathrm{c}$ ratio, the compressive, tensile and bending strengths all increased with increasing filling paste ratio. The tensile strength and the bending strength were 4 times of the compressive strength. Both porosity and the permeability coefficient decreased with increasing filling paste ratio. The relationship between connected porosity and the permeability coefficient is linear.

Bricks are a widely used for construction and building purposes around the world. Conventional bricks are made from clay with high temperature firing from ordinary Portland cement concrete and have large carbon footmark. In world there is a shortage of natural material to produce the conventional bricks. For environmental protection and recycle of wastes extensive research has been conducted from waste materials (Lianyang Zhang, et al., (2013) [38]). A large variety of waste materials have been studied to produce bricks. The research can be divided into three categories based on waste materials firing, cementing and polymerization. Though much research has been conducted, to produce the commercial bricks from waste materials is still very restricted. The reasons are related for producing bricks from waste materials, the potential contamination from the waste materials, the absence of relevant standards, and the slow acceptance of waste materials-based bricks by public and industry. The different methods studied for producing bricks from waste materials can be divided into three general categories firing, cementing and polymerization. The firing and cementing methods are high energy consumption and large carbon footprint as the conventional brick production methods. Though polymerizations seem to be energy efficient and environmental concerns.

Brahim Safi, et al., ., (2013) [39] demonstrated the possibility of recycling waste polyethylene terephthalate fine amassed instead of sand to produce physical and mechanical properties of the selfcompacting mortars with plastic wastes. The physical and mechanical properties of SCMs were assessed and a corresponding study on micro structural interface of the plastic waste. The extents of physical and mechanical properties show that the density of materials with $50 \%$ of plastic waste gives better results than the percentage of the waste. Those mortars have a mechanical strength for lightweight materials a reduction of $15 \%$ and $33 \%$ and mortar containing 20-50\% plastic waste. A microscopic study of the interfacial zone plastic binder has an adhesion between plastic and cement paste. This plastic waste type can be used successfully as a fine amassed in self-compacting mortars. Being given that the selfcompacting mechanical test showed that the compressive strength at 28 days of self-compacting mortar containing up to $50 \%$ of plastic waste was acceptable for lightweight mortars with the bulk density $1.5 \mathrm{~kg} / \mathrm{m}^{3}$.

MojtabaValinejadShoubi, et al., (2013) [40] One of the main drawbacks of constructing house is the high cost of the materials. Due to the high cost of constructing materials, the houses to be constructed under poverty line which is one of the most significant problem of people. A suitable approach for this situation is using some part of urban materials for construction of house and buildings. Plastic bottle is considered as a conventional material instead of brick in construction. This paper proposes to examine the application of plastic bottles also mention the ways for self-standing and insulating them in thermal and sound points of views. The end it concluded in different factors such as time of execution, cost, load capacity, elasticity, reducing waste and energy efficient. plastic bottles are more effective when compared to some conventional building materials such as brick, concrete and ceramic block. Plastic bottles are restrained as a kind of indecomposable waste which have considerable dangerous impact on environment. The plastic bottles can be used in some parts of building construction such as walls, roof etc. Reuse of the plastic bottles as the building materials can have extensive effects on saving the building signified energy by using them instead of bricks in walls and also it reduces the $\mathrm{CO} 2$ emission in manufacturing the cement by reducing the percentage of cement used.

\section{B. Findings in Plastic Bricks}




\section{International Journal of Engineering Applied Sciences and Technology, 2020 Vol. 4, Issue 12, ISSN No. 2455-2143, Pages 576-588 \\ Published Online April 2020 in IJEAST (http://www.ijeast.com)}

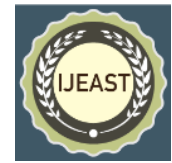

1. The compressive and tensile strength of the plastic brick is higher than the normal concrete brick used for construction.

2. It is inferred that the plastic brick material will have good properties used as thermal insulator material due to its high polymer content.

3. The use of marine sediment waste as the construction material can promote better weather resistance to the blocks.

4. The plasticwaste materials when effectively mixed with rubber powder and calcium carbonate gives the highest compressive strength which can bear the high compressive load.

5. Plastic bricks may appear strong, but it would deform under pressure.

6. The water absorption rates in the plastic brick are appeared to be less than other materials so that it can build a good bond between the aggregates, thus improving the mechanical strength of the permeable brick.

7. The firing and cementing methods are high energy consumption and large carbon footprint as the conventional brick production methods. Though polymerizations seem to be energy efficient and environmental concerns.

8. As such they would have a limited lifespan due to degradation by UV. Hot climate or direct contact to sun could make them soft. Extreme cold weather would make them brittle. Otherwise, they would crack in several years due to thermal cycling.

\section{CONCLUSION}

Thus the presented study helps in reducing the plastic waste disposal problem as it utilizes the waste and converts it into a useful construction material. Extruder machine plays a prominent role in the adaptation of waste plastic into its melted form. Also, extruder does not possess any threats to the environment and hence it can be used without any restriction. It also helps in reducing the usage of natural resources which are employed during the manufacturing of burnt bricks, also it reduces the pollution which is generated from kiln during brick manufacturing. The final end product can be used as brick, which is having a higher strength than conventional brick. Also, the water absorption capacity is higher in comparison to conventional brick with a lower weight. Its uses are not restricted as only brick; it can even be utilized as a building block by increasing the dimension of the mould. Also, it reduces the use of wire used for fencing. Floor tiles, sleepers, etc. can also be produced from it. This brick also turns out to be economical than conventional brick, by reducing the cost of incinerators for burning purpose and landfills.

\section{ACKNOWLEDGEMENT}

We wish to convey our sincere thanks to our project guide, Dr. R. Suresh Kumar for guiding us in a right way by motivating and clearing our doubts related to our project/review and also to our faculties who empowered our knowledge.

\section{REFERENCE}

[1] P.O. Awoyera, A. Adesina. (2020). 'Plastic wastes to construction products: Status, limitations and future perspective' - Case Studies in Construction Materials, $12 \mathrm{e} 00330$.

[2] Samuel Kofi Tulashie, Enoch Kofi Boadu, Francis Kotoka, David Mensah. (2020). 'Plastic wastes to pavement blocks: A significant alternative way to reducing plastic wastes generation and accumulation in Ghana' - Construction and Building Materials, 241118044

[3] Melina Gómez a, Lucas Ernesto Peisino, JerónimoKreiker, RosanaGaggino a, Ariel Leonardo Cappelletti, Sandra E. Martín, Paula M. Uberman, MaríaPositieri, Bárbara BelénRaggiotti. (2020). 'Stabilization of hazardous compounds from WEEE plastic: Development of a novel coreshell recycled plastic aggregate for use in building materials' - Construction and Building Materials, 230116977

[4] Alejandra Vidales-Barriguete, EvangelinaAtanesSánchez, Mercedes del Río-Merino, Carolina PiñaRamírez. (2020). 'Analysis of the improved waterresistant properties of plaster compounds with the addition of plastic waste' - Construction and Building Materials, 230116956

[5] Zhiqiang Yang, ZhiqinQiang, Min Guo, Guilan Yi, Yonglin Shi, Fangqin Cheng, Mei Zhang. (2020). 'Pilot and industrial scale tests of high-performance permeable bricks producing from ceramic waste' Journal of Cleaner Production, 254120167

[6] Isaac I. Akinwumi, Ayebaemi H. Domo-Spiff, Adeniyi Salami. (2019). 'Marine plastic pollution and affordable housing challenge: Shredded waste plastic stabilized soil for producing compressed earth bricks' - Case Studies in Construction Materials, 11e00241

[7] M.K. Mondal, B.P. Bose, P. Bansal. (2019). 'Recycling waste thermoplastic for energy efficient construction materials: An experimental investigation' - Journal of Environmental Management, 240119-125

[8] P. Pooja, ManendraVaitla, GudapatiSravan, Mt. Purusotham Reddy, Bhagyawati.M. (2019). 'Study on Behavior of Concrete with Partial Replacement of Fine Aggregate with Waste Plastics' - Materials Today: Proceedings, $8182-187$

[9] Gyanendra Kumar, Sandeep Shrivastava, R.C. Gupta. (2019). 'Paver blocks manufactured from 


\section{International Journal of Engineering Applied Sciences and Technology, 2020 \\ Vol. 4, Issue 12, ISSN No. 2455-2143, Pages 576-588 \\ Published Online April 2020 in IJEAST (http://www.ijeast.com)}

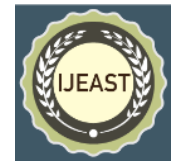

construction \& demolition waste' - Materials Today: Proceedings, 310212-217

[10] JeevanGhuge, SaurabhSurale, Dr. B.M. Patil, S B Bhutekar. (2019). 'Utilization of Waste Plastic in Manufacturing of Paver Blocks, e-ISSN2395-0056

[11] P. LalzarlianaPaihtea, Andy C. Lalngaihawmaa and Gaurav Sainia. (2019). 'Recycled Aggregate filled waste plastic bottles as a replacement of Bricks' Materials Today: Proceedings, 15663-668

[12] V. Moyo, N. G. Mguni, N. Hlabangana, G. Danha. (2019). 'Use of coal fly ash to manufacture a corrosion resistant brick' - Procedia Manufacturing, $35500-512$

[13] R. S. Kognole, KiranShipkule, Manish Patil, LokeshPatil, UdaysinhSurvase. (2019). 'Utilization of Plastic waste for Making Plastic Bricks', e-ISSN: $2456-6470$

[14] Ngoc Kien Bui, Tomoaki Satomi, Hiroshi Takahashi. (2018). 'Recycling woven plastic sack waste and PET bottle waste as fibre in recycled aggregate concrete: An experimental study' - Waste Management, 7879-93

[15] Zipeng Zhang, Yat Choy Wonga, Arul Arulrajah, SuksunHorpibulsuk. (2018). 'A review of studies on bricks using alternative materials and approaches' - Construction and Building Materials, 1881101-1118

[16] YaziMenga, Tung-Chai Linga, Kim Hung Mo. (2018). 'Recycling of wastes for value-added applications in concrete blocks: An Overview' Resources, Conservation \& Recycling, 138298-312

[17] P. Rubio-de Hita, F. Perez-Galvez, M.J. MoralesConde, M.A. Pedre no-Rojas. (2018). 'Reuse of plastic waste of mixed polypropylene as aggregate in mortars for the manufacture of pieces for restoring jack arch floors with timber beams' Journal of Cleaner Production, 1981515e1525

[18] ArvindSinghal, Dr.OmprakashNetula. (2018). 'Utilization of Plastic Waste in Manufacturing of Plastic Sand Bricks', ISSN-2349-5162

[19] Arul Arulrajah, Ehsan Yaghoubi, Yat Choy Wongb, SuksunHorpibulsuk. (2017). 'Recycled plastic granules and demolition wastes as construction materials: Resilient moduli and strength characteristics' - Construction and Building Materials, 147639-647

[20] Gaurav Goel, Ajay S. Kalamdhad. (2017). 'Degraded municipal solid waste as partial substitute for manufacturing fired bricks' Construction and Building Materials, 155259-266
[21] Valeria Gregorovaa, Miriam Ledererovaa, ZuzanaStefunkova. (2017). 'Investigation of Influence of Recycled Plastics from Cable, Ethylene Vinyl Acetate and Polystyrene Waste on Lightweight Concrete Properties' - Procedia Engineering, $195127-133$

[22] Mr. N. Thirugnanasambantham, P. Tharun Kumar, R. Sujithra, R. Selvaraman, P. Bharathi. (2017. 'Manufacturing and Testing of Plastic Sand Bricks', 3221 5687, (P) 3221 568X

[23] KateřinaNovákováa, KarelŠepsb, Henri Achten. (2017). 'Experimental Development of a Plastic Bottle Usable as a Construction Building Block Created Out of Polyethylene Terephthalate: testing PET(b)rick, S2352-7102(16)30276-5

[24] Sankuru Naresh, S.S. Asadi, A.V.S. Prasad. (2017). 'Design and Estimation of Eco Friendly Rigid Pavement with Geo Plastic bricks in Rural Areas', ISSN Print: 0976-6308 and ISSN Online: 09766316

[25] K. Prem Kumar1, M. Gomathi. (2017). 'Production of Construction Bricks by Partial Replacement of waste Plastics', e-ISSN: 2278-1684, p-ISSN: 2320$334 X$

[26] Md. Jahidul Islam, Md. SalamahMeherier, A.K.M. Rakinul Islam. (2016). 'Effects of waste PET as coarse aggregate on the fresh and harden properties of concrete' - Construction and Building Materials, 125946-951

[27] Ayse KAYA, Filiz KAR. (2016). 'Properties of concrete containing waste expanded polystyrene and natural resin' - Construction and Building Materials, 105572-578

[28] AshwiniManjunath B T. (2016). 'Partial replacement of E-plastic Waste as Coarse-aggregate in concrete' - Procedia Environmental Sciences, $35731-739$

[29] SinaSafinia, Amani Alkalbani. (2016). 'Use of recycled plastic water bottles in concrete blocks' Procedia Engineering, 164214 - 221

[30] Z Muyen, TN Barna, MN Hoque. (2016). 'Strength properties of plastic bottle bricks and their suitability as construction materials in Bangladesh' - Progressive Agriculture, 27 (3): 362-368

[31] Rohan Muni Bajracharya, Allan C. Manalo, WarnaKarunasena, Kin-tak Lau. (2015). 'Characterisation of recycled mixed plastic solid wastes: Coupon and full-scale investigation' Waste Management, 516102-108

[32] Lara P. Rodriguesa, José Nilson F. Holanda. (2015). 'Recycling of Water Treatment Plant Waste 
for Production of Soil-Cement Bricks' - Procedia Materials Science, $8197-202$

[33] Noel Deepak Shiri, P. VarunKajava, Ranjan H. V., Nikhil Lloyd Pais, Vikhyat M. Naik. (2015). 'Processing of Waste Plastics into Building Materials Using a Plastic Extruder and Compression Testing of Plastic Bricks', p-ISSN: 2163-2405 e-ISSN: 2163-2413; 5(3B): 39-42

[34] Chong-Qing Wang, Hui Wang 爪, You-Nian Liu. (2014). 'Separation of polyethylene terephthalate from municipal waste plastics by froth flotation for recycling industry' - Waste Management, 222212217

[35] L. Rigamontia, M. Grossoa, J. Møllerb, V. Martinez Sanchezb, S. Magnania, T.H. Christensen. (2014). 'Environmental evaluation of plastic waste management scenarios' - Resources, Conservation and Recycling, 8542- 53

[36] Jonathan Taaffe, Sean O'Sullivan, Muhammad Ekhlasur Rahman, VikramPakrashi. (2014). 'Experimental characterisation of Polyethylene Terephthalate (PET) bottle Eco-bricks' - Materials and Design, 6050-56

[37] Wen-Ten Kuo, Chih-Chien Liu b, De-Sin Su. (2013). 'Use of washed municipal solid waste incinerator bottom ash in pervious concrete' Cement \& Concrete Composites, 37328-335

[38] Lianyang Zhang. (2013). 'Production of bricks from waste materials - A review' - Construction and Building Materials, 47643-655

[39] Brahim Safi, Mohammed Saidi, DjamilaAboutaleb, MadaniMaallem. (2013). 'The use of plastic waste as fine aggregate in the self-compacting mortars: Effect on physical and mechanical properties' Construction and Building Materials, 43436-442

[40] MojtabaValinejadShoubi, AzinShakibaBarough. (2013). 'Investigating the Application of Plastic Bottle as a sustainable material in the Building construction', ISSN: 2278 - 7798. 